\title{
Parametric Study of Rupture Analysis for the Optimization of Stable Emulsion Liquid Membrane using DOE Approach
}

\author{
Raja Fahad Qureshi' ${ }^{1 a}$, Inamullah Bhatti² ${ }^{2}$ Khadija Qureshi $^{3}$, Sanam Irum Memon ${ }^{1 b}$
}

RECEIVED ON 18.12.2018, ACCEPTED ON 03.05.2019

\begin{abstract}
Rupture of the membrane is considered as one of the most critical characteristics while working on wastewater treatment via emulsion liquid membrane. This paper presents a decisive study of different parameters affecting the rupture of membrane. The potential parameters which are investigated in this study include, surfactant dosage, surfactant concentration, concentration of aqueous phase, emulsification velocity, ratio of organic to aqueous phases and ratio of membrane to feed phases. The Design of Experiment (DOE) approach was used to design the experiments and the results were analyzed statistically through a software Minitab-18. The study revealed that amongst all these parameters, two are the highly significant playing a crucial role in rupture of the membrane. These significant parameters are emulsification velocity and ratio of the organic to aqueous phase. Pareto chart being used as an effective statistical tool implied that the emulsification velocity and ratio of the organic to aqueous phase have negative and positive effects on the response respectively. Using the Response Optimizer tool, the optimum levels of all the potential parameters were statistically calculated followed by an experimental verification resulting a least minimum rupture of $36 \%$. A statistical model was developed in this study and the values of predicted rupture were compared with the experimental results. The calculated correlation coefficient $R^{2}$ of the developed model was 0.998 and the accuracy of correlation coefficient deduced that the developed model of rupture will precisely calculate the rupture over the range of values.
\end{abstract}

Keywords: Rupture, Emulsification, Emulsion Liquid Membrane, Design of Experiment

\section{INTRODUCTION}

$\mathrm{T}$ Treatment of the contaminated wastewater is one of the most serious issues of concern for researchers in these days. Several methods have been demonstrated for the treatment of polluted water by different scientists. These methods may include coagulation [1-2], flocculation [3-4], adsorption [5-6], chemical oxidation [7-8] and photocatalytic processes [9-10]. Amongst all these treatment methods, separation of targeted species from wastewater through Emulsion Liquid Membranes (ELM) is also a promising technique. The concept of Emulsion Liquid Membranes was first proposed by $\mathrm{Li}$ [11]. This separation technique is based on selective permeation through a liquid surfactant membrane. Usually an organic solvent and water are the basic constituents to make an emulsion in any ELM system. Stability of such emulsion is stabilized by adding some suitable amount of surfactant. Later the emulsion is brought into contact with external feed phase that contains the targeted solute desired to be separated.

${ }^{1}$ Department of Textile Engineering, Mehran University of Engineering and Technology, Jamshoro, Pakistan.

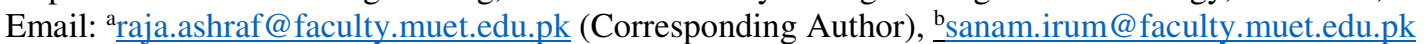

${ }^{2}$ Office of Research, Innovation and Commercialization, Mehran University of Engineering andTechnology, Jamshoro. Email: inamullah.bhatti@faculty.muet.edu.pk

${ }^{3}$ Department of Chemical Engineering, Mehran University of Engineering and Technology, Jamshoro, Pakistan. Email: khadija.qureshi@ faculty.muet.edu.pk

This is an open access article published by Mehran University of Engineering and Technology, Jamshoro under CC BY 4.0 International License. 


\section{Parametric Study of Rupture Analysis for the Optimization of Stable Emulsion Liquid Membrane using DOE Approach}

Blending of emulsion and feed phase results in globule formation and transportation through the slim membrane layer that splits internal phase droplets within the emulsion globules. An oil-in-water emulsion dispersed in oil $(\mathrm{O} / \mathrm{W} / \mathrm{O})$ or a water-in-oil emulsion dispersed in an aqueous phase $(\mathrm{W} / \mathrm{O} / \mathrm{W})$ are two main paradigms of three phase dispersion in ELM systems. According to Ho [12], the diameter of the emulsion globules is generally $0.1-2.0 \mathrm{~mm}$ which is quite larger than the diameter of internal phase droplets measuring approximately 1-10 $\mu \mathrm{m}$. Extraction of any solute with ELMs system usually ends up with the demulsification (breakup) of emulsion in order to reclaim the internal phase comprising of the targeted solute.

ELMs are highly efficient in situation where the targeted solute in the feed flow is in lowest concentration [13]. ELMs provide tremendously a huge membrane surface area for the extraction of desired solutes. High efficiency with easy procedure, extraction and stripping in one stage, large interfacial area and scope for continuous operation are some of the smart features of ELM systems [14].

However, apart from many advantages, the behavior of ELM encounters some drawbacks also like other treatment processes. Rupture of the membrane is one of these drawbacks, usually put up with researchers. Rupture occurs due to the leakage of stripping agent's ion from internal aqueous phase into the external feed phase thus by altering its $\mathrm{pH}$. This state indicates the instability of the ELM which is exceptionally undesirable to achieve maximum efficiency of the system. In design of any ELM system, there are certain parameters playing a major role in the rupture of membrane [15]. These parameters require some optimum levels during the preparation of an ELM to achieve maximum efficiency with minimum rupture. DOE is a statistical technique used to identify key factors and levels that influence system performance and variability [16]. This technique is especially useful when there is need to understand the interactions and effects of system variables in an absence of concrete information [17]. This research article focuses on the parametric study of all these factors and finding the most significant one among them along with their effect on formulated system. This study uses statistical approach of DOE to optimize and statistically analyze the parameters affecting rupture of the ELM.

\section{EXPERIMENTAL}

\subsection{Reagents and Material}

Sulphuric acid $\left(\mathrm{H}_{2} \mathrm{SO}_{4}\right)$ supplied by Merck was used as internal aqueous phase in this study. Organic phase was consisted of an analytical reagent grade Hexane and Span-80 as organic diluent and surfactant respectively. Hexane was supplied by Fisher Scientific (UK) while Span-80 was obtained from SigmaAldrich. Double distilled water was used as external feed phase in this study. Emulsification of organic and aqueous phases was carried out by ULTRA-Turax T25 Homogenizer. ADVANTEC MIDGET mechanical stirrer attached with a four bladed propeller type shaft was used in this study for mixing of W/O emulsion with external feed phase. For gentle mixing of required ingredients in aqueous and organic phases, WISE-STIR magnetic stirrer was used.

\subsection{Procedure \\ 2.2.1 Membrane Preparation}

Internal aqueous phase was prepared by taking the required amount of $\mathrm{H}_{2} \mathrm{SO}_{4}$ in distilled water. The organic phase was prepared by dissolving the appropriate amount of Span-80 as a surfactant in Hexane at $30^{\circ} \mathrm{C}$ for 15 minutes on magnetic stirrer. The stirring speed of the magnetic stirrer was fixed at $500 \mathrm{rpm}$. The W/O emulsion membrane was prepared by mixing the two phases (aqueous and organic) using ULTRA-Turax T-25 Homogenizer at different homogenizing speed by varying emulsification time. Aqueous phase was poured in the Organic phase drop wise.

\subsubsection{Rupture Analysis}

In order to analyze the rupture of membrane, the emulsion in this manner formed was dispersed with feed phase. Feed phase in this study is usually distilled water having neutral $\mathrm{pH}$. Breakup of the emulsion is typically deduced by observing a change in the $\mathrm{pH}$ of distilled water which occurs due to the eviction of $\mathrm{H}_{2} \mathrm{SO}_{4}$ from internal aqueous phase to feed phase. 


\section{Parametric Study of Rupture Analysis for the Optimization of Stable Emulsion Liquid Membrane using DOE Approach}

Distilled water as feed phase contained in a glass beaker was put under revolving shaft of an overhead mechanical stirrer and W/O emulsion was poured gradually in it. A W/O/W double emulsion was finally made by stirring the contents of the glass beaker at various contact times and rotational speeds. Tracer Method was chosen in this study to calculate the rupture rate of the formulated ELM system [18]. The rupture rate $(\varepsilon)$ can be simply understood as the percentage of the volume of the internal aqueous phase $\left(\mathrm{V}_{\mathrm{s}}\right)$ expelled by breaking into the external feed phase with respect to the initial volume of the internal phase $\left(\mathrm{V}_{\mathrm{i}}\right)$. Rupture rate $(\varepsilon)$ can be calculated from the Equation (1):

$$
\varepsilon=\frac{\mathrm{V}_{\mathrm{s}}}{\mathrm{V}_{\mathrm{i}}} \times 100
$$

The volume of the internal phase leaked into the external phase (Vs) is calculated by equation of massbalance Equation (2).

$$
\mathrm{V}_{\mathrm{s}}=\mathrm{V}_{\mathrm{Ext}} \frac{10^{-\mathrm{pH}_{0}}-10^{-\mathrm{pH}}}{10^{-\mathrm{pH}}-\mathrm{C}_{\mathrm{H}^{+}}^{\mathrm{i}}}
$$

where $\mathrm{V}_{\text {Ext }}$ is the initial volume of external phase, $\mathrm{C}_{\mathrm{H}+}^{\mathrm{i}}$ is the initial concentration of $\mathrm{H}^{+}$in the internal phase, $\mathrm{pH}_{0}$ is the initial $\mathrm{pH}$ of the external phase and $\mathrm{pH}$ is the external phase $\mathrm{pH}$ being in contact with the emulsion after a certain time of stirring. In this study, $\mathrm{H}_{2} \mathrm{SO}_{4}$ is used as stripping agent in internal aqueous phase so $\mathrm{H}+$ ion is a targeted tracer which can be easily detected by a $\mathrm{pH}$ meter. BANTE Instruments $\mathrm{pH}$ meter was used to determine the variation in $\mathrm{pH}$ and to calculate the hydrogen ion concentration thus analyzing the rupture of membrane.

\section{RESULTS AND DISCUSSION}

\subsection{Screening Design \\ 3.1.1 Experimental Results}

Table 1 show a list of six parameters which were altered simultaneously in this study to perform the rupture analysis of the formulated membrane. A wellknown statistical technique of DOE was used to design the experiments and results were analyzed via Taguchi method with help of MINITAB-18 software. Review

\begin{tabular}{|c|c|c|}
\hline \multicolumn{2}{|c|}{$\begin{array}{c}\text { TABLE 1. PARAMETERS WITH MINIMUM } \\
\text { AND MAXIMUM LEVELS }\end{array}$} \\
\hline Parameter & $\begin{array}{c}\text { Minimum } \\
\text { Level }\end{array}$ & $\begin{array}{c}\text { Maximum } \\
\text { Level }\end{array}$ \\
\hline $\begin{array}{c}\text { Surfactant Dosage } \\
(\%)\end{array}$ & 2 & 5 \\
\hline $\begin{array}{c}\text { Aqueous Phase } \\
\text { Concentration } \\
\text { (Molarity) }\end{array}$ & 0.1 & 1 \\
\hline Stirring Speed (rpm) & 100 & 500 \\
\hline $\begin{array}{c}\text { Emulsification Speed } \\
\text { (rpm) }\end{array}$ & 3000 & 8000 \\
\hline $\begin{array}{c}\text { Ratio } \\
\text { Membrane/Feed }\end{array}$ & 2 & 5 \\
\hline $\begin{array}{c}\text { Ratio } \\
\text { Organic/Aqueous } \\
\text { Phases }\end{array}$ & 1 & 2 \\
\hline
\end{tabular}

of the related literature and preliminary tests earlier performed helped out to select the maximum and minimum levels of each parameter in the design.

\begin{tabular}{|c|c|c|c|c|c|c|c|}
\hline \multicolumn{7}{|c|}{ TABLE 2. EXPERIMENTAL ARRAY WITH EXPERIMENTALLY OBTAINED RESULTS } \\
\hline $\begin{array}{c}\text { Run } \\
\text { Order }\end{array}$ & $\begin{array}{c}\text { Surfactant } \\
\text { Dosage } \\
(\%)\end{array}$ & $\begin{array}{c}\text { Ratio } \\
\text { Organic/Aqueous } \\
\text { Phases }\end{array}$ & $\begin{array}{c}\text { Ratio } \\
\text { Membrane/Feed }\end{array}$ & $\begin{array}{c}\text { Aqueous } \\
\text { Phase } \\
\text { Concentration } \\
\text { (Molar) }\end{array}$ & $\begin{array}{c}\text { Stirring } \\
\text { Speed } \\
(\mathrm{rpm})\end{array}$ & $\begin{array}{c}\text { Emulsification } \\
\text { Speed } \\
(\mathrm{rpm})\end{array}$ & $\begin{array}{c}\text { Rupture } \\
(\%)\end{array}$ \\
\hline 1 & 2 & 1 & 5 & 0.1 & 500 & 8000 & 41.8 \\
\hline 2 & 2 & 1 & 2 & 0.1 & 100 & 3000 & 53.2 \\
\hline 3 & 2 & 2 & 2 & 1 & 500 & 8000 & 60.0 \\
\hline 4 & 5 & 2 & 5 & 0.1 & 100 & 8000 & 59.4 \\
\hline 5 & 5 & 2 & 2 & 0.1 & 500 & 3000 & 73.5 \\
\hline 6 & 2 & 2 & 5 & 1 & 100 & 3000 & 79.7 \\
\hline 7 & 5 & 1 & 2 & 1 & 100 & 8000 & 39.3 \\
\hline 8 & 5 & 1 & 5 & 1 & 500 & 3000 & 56.5 \\
\hline
\end{tabular}




\section{Parametric Study of Rupture Analysis for the Optimization of Stable Emulsion Liquid Membrane using DOE Approach}

A summarized run order with 8 runs of fractional factorial plan was prepared with totally randomized array and the rupture rate was experimentally calculated. The rupture rate experimentally obtained according to experimental design with different run orders is illustrated in Table 2 .

\subsubsection{Discussion}

Pareto chart of effects is an eminent technique to identify the most important factor/s in any parametric study statistically. In this study this chart was also statistically obtained to make out the factors, significant in the rupture study. The effect of these parameters on the rupture was investigated using a statistical tool; Main effects plot. Figs. 1-2 represent the Pareto chart and main effect plot for the rupture of prepared ELM system respectively.
Pareto chart of effects in Fig. 1 revealed that ratio of the organic to aqueous phase and emulsification velocity and are two mainly influencing and imperative factors over the existing study. Rest of the factors play a role but of less significance. Fig. 1 also Amongst all the six parameters studied as showed in discovered the effect of interaction between stirring speed and aqueous phase concentration, however this is negligible. Fig. 2 describes the main effect plot that assists in discovering the influence of all the potential parameters for level changes.

Fig. 2, the main effects plot revealed that the four parameters effects positively on the response (i.e. rupture). The ratio of the organic to aqueous phase shows the positive and highest effect on the system. Two other factors, ratio of membrane to feed phase and concentration of aqueous phase also show a

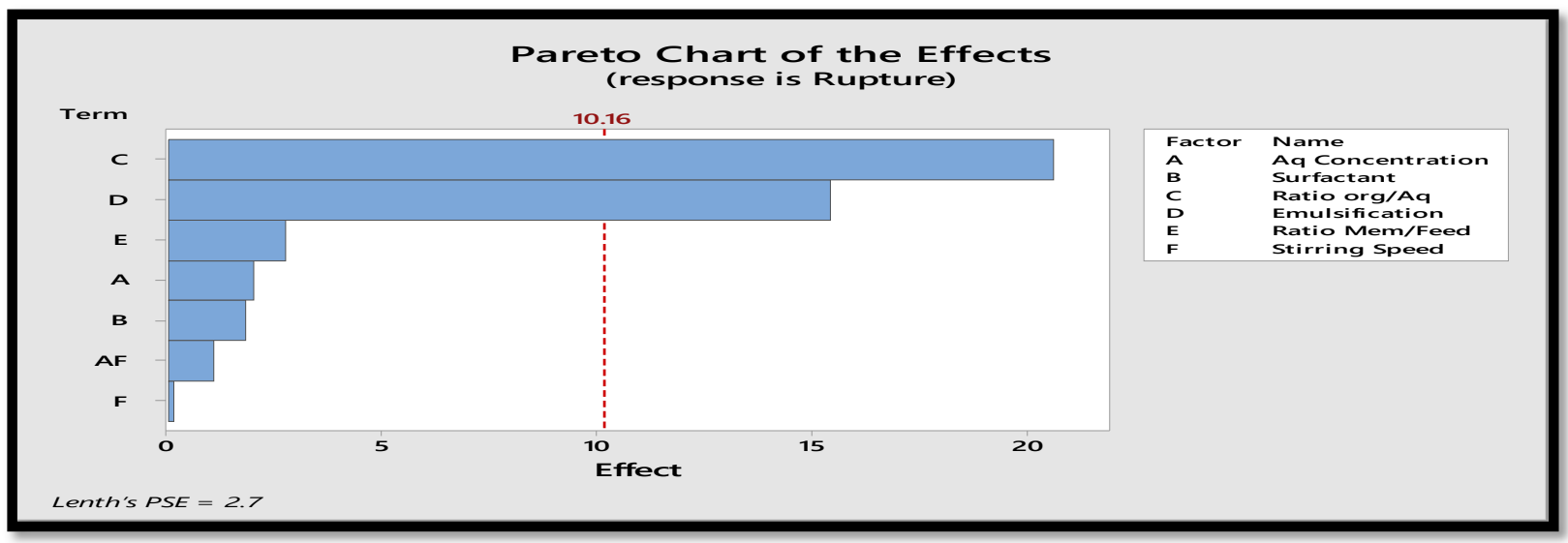

FIG. 1. PARETO CHART OF EFFECTS FOR RUPTURE AS RESPONSE

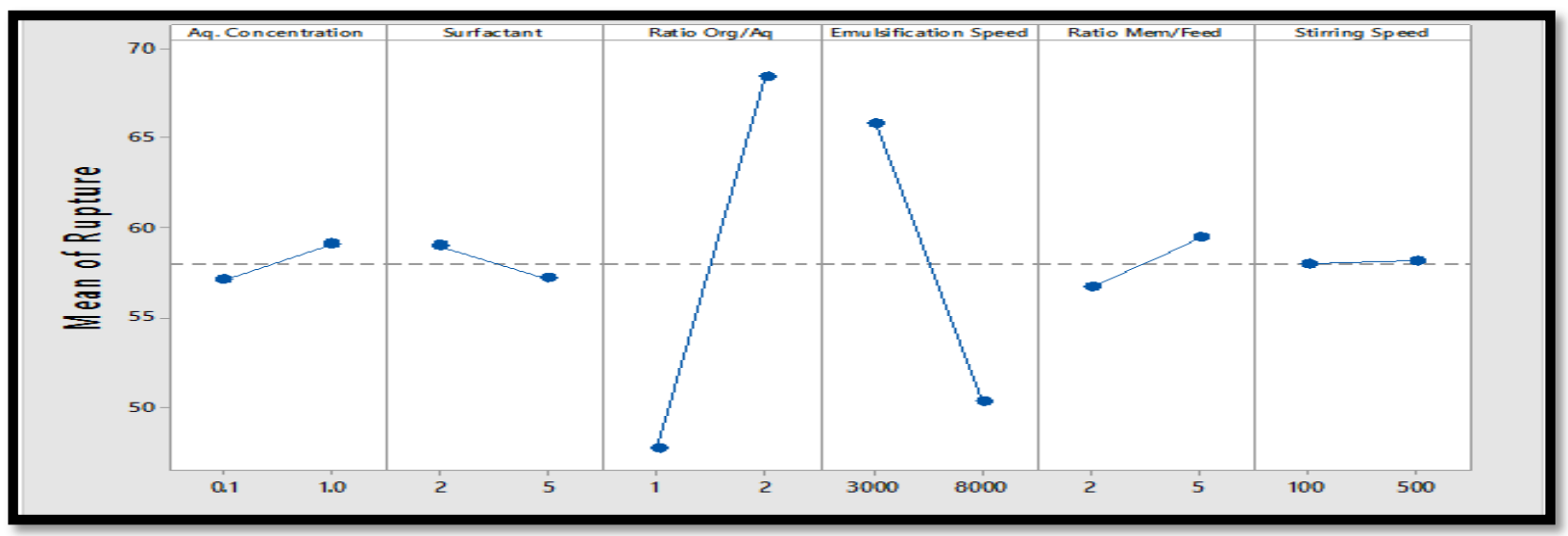

FIG. 2. MAIN EFFECTS PLOT OF PARAMETERS FOR RUPTURE ANALYSIS 


\section{Parametric Study of Rupture Analysis for the Optimization of Stable Emulsion Liquid Membrane using DOE Approach}

positive response but the response level of these parameters is lower than the previous one. Stirring speed as the fourth parameter with positive effect on the system signifies negligible impact. The remaining two parameters in the current study; surfactant dosage and emulsification speed infer the negative effect on the response. This negative response is considerable in case of emulsification speed as potential parameter, however in case of surfactant dosage, it is almost negligible.

P-values of the parameters affecting the rupture of ELM along with their coefficients are illustrated in Table 3. The negative effect of the subsequent parameters can be identified by the negative sign before the coefficient value. The significance of the operating factors on any experimental system can be determined by an efficient statistical tool known as $\mathrm{P}$ value [19]. If any effect is significant then there will be high probability that the effect is "real". Significance level obtained more than $95 \%$ is usually considered good in any experimental study. It is simply calculated by using the expression:

Significance $(\%)=\frac{1-(\mathrm{P}-\text { Value })}{100}$

From Table 3, it can be seen that volume ratio of organic to Aqueous Phase has P-Value of 0.03 that means this parameter has $97 \%$ significance over the rupture response of the formulated emulsion liquid membrane. Emulsification speed is the second most significant factor with significance level of $96 \%$.

\section{STATISTICAL MODEL FOR THE ANALYSIS OF RUPTURE}

The approach of DOE in any experimental study assists to design a statistical model also. This model helps in forecasting the overall result of a system while changing the levels of any/all of the operating parameters. In this study, statistical model (Equation (4)) was also developed which afterward used to obtain predicted results according to the experimental array mentioned in Table 2. Validity of the proposed model was assessed by comparing the predicted results with experimental results. Table 4 shows the experimental results and estimated results of the rupture analysis of the ELM.

Rupture $=41.55+2.22$ (Aq. Phase Concentration) 0.600 (Surfactant Dosage) +20.65 (Ratio Org/Aq. Phase) - 0.003080(Emulsification Speed) + 0.917(Ratio Membrane/Feed Phase) + 0.3050(Emulsification Time)

\begin{tabular}{|c|c|c|}
\hline \multicolumn{3}{|c|}{ TABLE 3. PARAMETERS WITH THEIR P- } \\
VALUES AND COEFFICIENTS \\
\hline Parameter & P-Value & Coefficient \\
\hline Intercept & 0.045684 & 41.54694 \\
\hline $\begin{array}{c}\text { Ratio Organic to } \\
\text { Aqueous Phase }\end{array}$ & 0.03378 & 20.66 \\
\hline $\begin{array}{c}\text { Ratio Membrane to Feed } \\
\text { Phase }\end{array}$ & 0.242228 & 0.916666 \\
\hline Surfactant Dosage (\%) & 0.349227 & -0.61 \\
\hline $\begin{array}{c}\text { Emulsification Speed } \\
\text { (rpm) }\end{array}$ & 0.045386 & -0.00309 \\
\hline $\begin{array}{c}\text { Aqueous Phase } \\
\text { Concentration (molar) }\end{array}$ & 0.32022 & 2.2222222 \\
\hline Stirring Speed (rpm) & 0.91382 & 0.000376 \\
\hline
\end{tabular}

\begin{tabular}{|c|c|c|}
\hline \multicolumn{3}{|c|}{ TABLE 4. COMPARISON IN PREDICTED } \\
AND EXPERIMENTAL RESULTS
\end{tabular}

Proximity of the experimental and the predicted results mentioned in Table 4 indicates that the model is very representative for the current study of rupture analysis. Fig. 3 represents a graph illustrating the predicted and experimental values plotted on it. The values are reasonably distributed in the region of the regression line. The value of correlation constant $\mathrm{R}^{2}$ was calculated as 0.997 indicating the excellence of fit and validation of the model. 


\section{Parametric Study of Rupture Analysis for the Optimization of Stable Emulsion Liquid Membrane using DOE Approach}

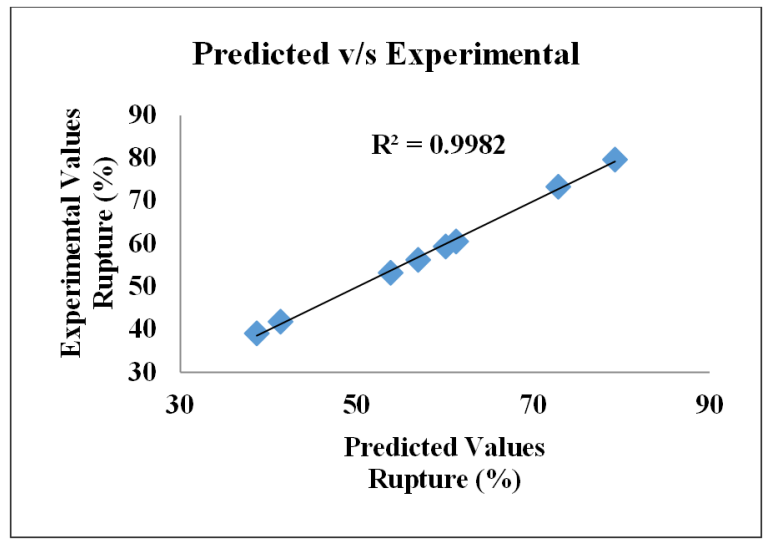

FIG. 3. CORRELATION BETWEEN PREDICTED AND EXPERIMENTAL RESULTS

\section{OPTIMIZATION OF THE PARAMETERS}

The operating parameters were optimized statistically in order to minimize the rupture of ELM observed in this study. Fig. 4 shows the optimum levels of all the operating parameters corresponding in this experimental design to a minimum of the rupture achieved.

According to response optimizer shown in Fig. 4, the rupture could be minimized up to 36.1 if overall factors were set according to solution described in Table 5.

A verification of the optimum conditions was carried out twice in the same experimental setup. The rupture was obtained with the mean result of $36 \%$.
TABLE 5. SOLUTION FOR OBTAINING THE MINIMUM RUPTURE

\begin{tabular}{|l|l|}
\hline Solution & 1 \\
\hline Aq.Phase Concentration (M) & 0.1 \\
\hline Surfactant Dosage (\%) & 5 \\
\hline Ratio Org/Aq. Phases & 1 \\
\hline Emulsification Speed (rpm) & 8000 \\
\hline Ratio Membrane/Feed Phases & 2 \\
\hline Stirring Speed (rpm) & 100 \\
\hline Desirability & 1 \\
\hline Rupture Fit (\%) & 36.1 \\
\hline
\end{tabular}

\section{CONCLUSION}

An approach of DOE used in this study discovered the significant parameters affecting the rupture of an ELM system. Main effect plot revealed that the ratio of the organic to aqueous phase and emulsification speed are two main parameters playing a significant role in rupture study. Statistical tool of Pareto chart implied that the ratio of organic to aqueous phase imparts a positive effect on rupture of ELM while the emulsification speed has negative impact. A statistical model was also developed and results of estimated and experimental values were compared. Correlation constant $\mathrm{R}^{2}$ value was calculated as 0.998 which indicated that the data fits the model well. Response optimizer tool was used to obtain the optimum levels of all operating parameters influencing the rupture of ELM. These obtained optimized values were experimentally verified and found them satisfactory

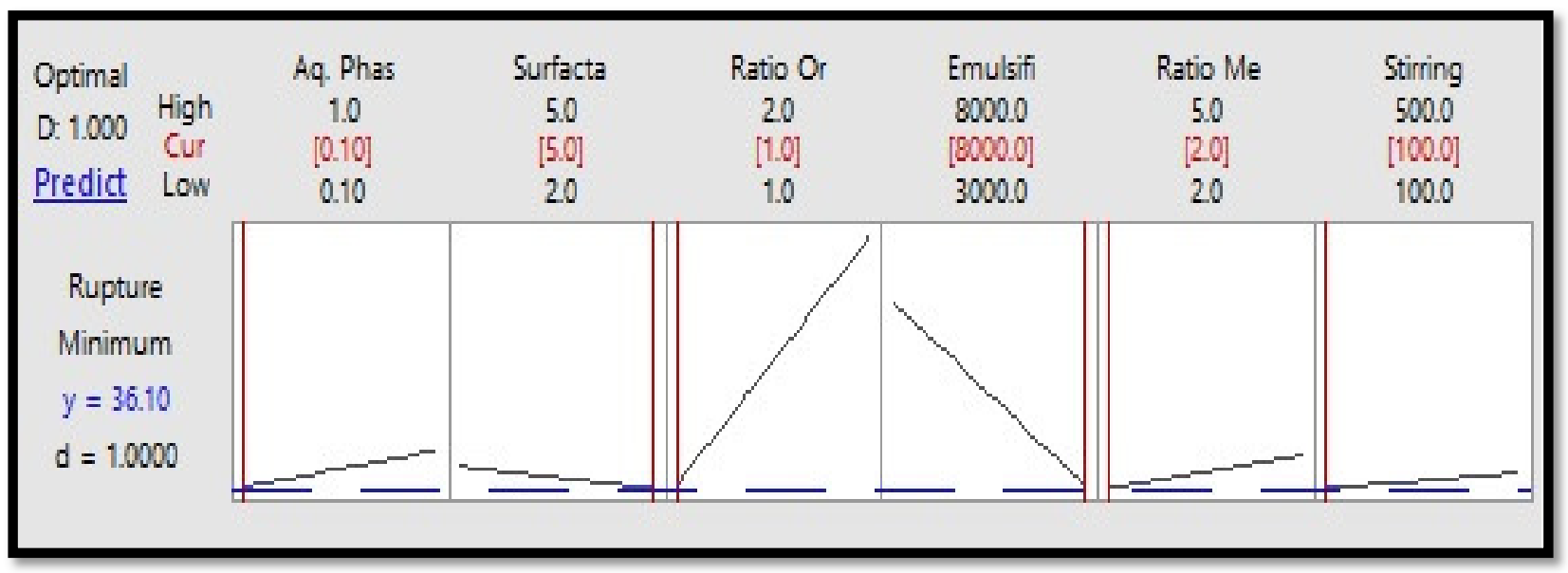

FIG. 4. RESPONSE OPTIMIZER PLOT SHOWING OPTIMUM LEVELS OF PARAMETERS 


\section{Parametric Study of Rupture Analysis for the Optimization of Stable Emulsion Liquid Membrane using DOE Approach}

giving the minimum possible rupture of $36 \%$ for the studied ELM. This study would be very supportive to control the rupture of membrane in order to obtain the maximum efficiency of ELM systems.

\section{ACKNOWLEDGEMENT}

The authors wish to offer their gratitude to Mehran University of Engineering \& Technology, Jamshoro for providing financial support and required resources to carry out this research. Authors also greatly acknowledge the services provided by Water Quality Lab of Chemical Engineering Department, MUET, Jamshoro throughout this study.

\section{REFRENCES}

[1] Barbosa, A. D., da Silva L. F., de Paula, H. M., Romualdo, L. L., Sadoyama, G., and Andrade, L. S., "Combined use of coagulation (M. oleifera) and electrochemical techniques in the treatment of industrial paint wastewater for reuse and/or disposal", Water Research, Vol. 145, pp. 153-161, 2018.

[2] Kumar, A., Nidheesh, P. V., and Suresh Kumar, M., "Composite wastewater treatment by aerated electrocoagulation and modified peroxi-coagulation processes," Chemosphere, Vol. 205, pp. 587-593, 2018.

[3] Choumane, F., Benguella, Z. B., Maachou B., and Saadi, N., "Valorisation of a bioflocculant and hydroxyapatites as coagulation-flocculation adjuvants in wastewater treatment of the steppe in the wilaya of Saida (Algeria)," Ecological Engineering, Vol. 107, pp. 152-159, 2017.

[4] Suresh, A., Grygolowicz-Pawlak, E., Pathak, S., Poh, L. S., Abdul Majid, M. B., Dominiak, D., "Understanding and optimization of the flocculation process in biological wastewater treatment processes: A review," Chemosphere, Vol. 210, pp. 401-416, 2018.

[5] Leal, T. W., Lourenço, L. A., Scheibe, A. S., de Souza, S. M. A. G. U., and de Souza, A. A. U., "Textile wastewater treatment using low-cost adsorbent aiming the water reuse in dyeing process," Journal of Environmental
Chemical Engineering,Vol. 6, pp. 27052018.

[6] GilPavas, E. I. Dobrosz-Gómez, and M.-Á. Gómez-García, "Optimization and toxicity assessment of a combined electrocoagulation, $\mathrm{H} 2 \mathrm{O} 2 / \mathrm{Fe} 2+/ \mathrm{UV}$ and activated carbon adsorption for textile wastewater treatment," Science of The Total Environment, Vol. 651, pp. 551-560, 2019.

[7] Paździor, K., Bilińska, L., and Ledakowicz, S., "A review of the existing and emerging technologies in the combination of AOPs and biological processes in industrial textile wastewater treatment," Chemical Engineering Journal, Vol. 30, pp. 311-340, 2018.

[8] Silva, L. G. M., Moreira, F. C., Souza, A. A. U., Souza, S. M. A. G. U., Boaventura, R. A. R., and Vilar, V. J. P., "Chemical and electrochemical advanced oxidation processes as a polishing step for textile wastewater treatment: A study regarding the discharge into the environment and the reuse in the textile industry," Journal of Cleaner Production, Vol. 198, pp. 430-442, 2018.

[9] Jorfi, S., Pourfadakari, S., and Kakavandi, B., "A new approach in sono-photocatalytic degradation of recalcitrant textile wastewater using $\mathrm{MgO} @$ Zeolite nanostructure under UVA irradiation," Chemical Engineering Journal, Vol. 343, pp. 95-107, 2018.

[10] Abdelsamad, A. M. A., Gad-Allah, T. A., Mahmoud, F. A., and Badawy, M. I., "Enhanced photocatalytic degradation of textile wastewater using $\mathrm{Ag} / \mathrm{ZnO}$ thin films," Journal of Water Process Engineering,Vol. 25, pp. 88-95, 2018.

[11] Patnaik, P. R., "Liquid emulsion membranes: Principles, problems and applications in fermentation processes," Biotechnology Advances, Vol. 13, pp. 175-208, 1995.

[12] Bhatti, I., Qureshi, K., Kamarudin, K. S. N., Bazmi, A. A., Bhutto, A. W., Ahmad, F., "Innovative method to prepare a stable emulsion liquid membrane for high $\mathrm{CO}_{2}$ absorption and its performance evaluation for a natural gas feed in a rotating disk

Mehran University Research Journal of Engineering and Technology, Vol. 39, No. 3, July 2020 [p-ISSN: 0254-7821, e-ISSN: 2413-7219] 
contactor," Journal of Natural Gas Science and Engineering, Vol. 34, pp. 716-732, 2016.

[13] Hong S.-A. and Yang J.-W., "Process development of amino acid concentration by a liquid emulsion membrane technique," Journal of Membrane Science, Vol. 86, pp. 181-192, 1994.

[14] Itoh, H., Thien, M. P., Hatton, T. A., and Wang, D. I. C., "Water transport mechanism in liquid emulsion membrane process for the separation of amino acids," Journal of Membrane Science, Volume 51, pp. 309-322, 1990.

[15] Kargari, A., Kaghazchi, T., and Soleimani, M., "Role of emulsifier in the extraction of gold (III) ions from aqueous solutions using the emulsion liquid membrane technique," Desalination, Vol. 162, pp. 237-247, 2004.

[16] Asim, F. and Mahmood, M., "Statistical Modeling of Tear Strength for One Step Fixation Process of Reactive Printing and Easy Care Finishing," Mehran University Research Journal of Engineering and Technology,Vol. 36, No. 3, pp. 511-518, 2017.
[17] Asim, F., and Mahmood, M., "Effects of Process Parameters on Ozone Washing for Denim using $3^{3}$ Factorial Design," Mehran University Research Journal of Engineering and Technology,Vol. 36, No. 4, pp. 909-914, 2017.

[18] Djenouhat, M., Hamdaoui, O., Chiha, M., "Ultrasonication-assisted preparation of water-in-oil emulsions and application to the removal of cationic dyes from water by emulsion liquid membrane", Separation and Purification Technology, Vol. 62, No. 3, pp. 636-641, 2008.

[19] Qureshi, R. F., Qureshi, K., Bhatti, I., and Khatri, Z., "Statistical Modeling for Stability of Emulsion Liquid Membrane for the Removal of Anionic Dyes from Textile Wastewater," Mehran University Research Journal of Engineering and Technology, Vol. 37, No.3, pp. 631-638, 2018. 